\title{
HIBRIDEZ GENÉRICA Y UNIDAD ARTÍSTICA EN LA COMEDIA DE SANTOS: EL PROCESO \\ DE HIBRIDACIÓN EN LO FINGIDO VERDADERO
}

\author{
JAVIER RUBIERA (Université de Montréal)
}

CitA RECOMENDADA: Javier Rubiera, «Hibridez genérica y unidad artística en la comedia de santos: el proceso de hibridación en Lo fingido verdadero", Anuario Lope de Vega. Texto, literatura, cultura, XXVIII (2022), pp. 103-139.

DOI: <https://doi.org/10.5565/rev/anuariolopedevega.443>

Fecha de recepción: 9 de julio de 2021 / Fecha de aceptación: 1 de septiembre de 2021

\section{RESUMEN}

Este artículo explora el fenómeno de la hibridación genérica en una peculiar comedia hagiográfica de Lope de Vega, Lo fingido verdadero. Estudia de qué modo se integran en ella numerosos elementos de naturaleza heterogénea dentro de una estructura dramática móvil, en la que se combinan rasgos de drama histórico, comedia de capa y espada, comedia de enredo amoroso, tragedia y comedia de santos. Lope logra conferir unidad artística al conjunto de personajes y de acontecimientos de distinto género mediante un tema articulador de los tres actos (la metáfora del theatrum mundi), el juego de contraposición entre dos personajes protagonistas, y una red de recurrencias, simetrías, contrastes y símbolos (laurel y pan). Se tienen en cuenta la relación de la obra con sus fuentes y la comparación con otras comedias hagiográficas de Lope o con otros dramas españoles sobre la figura de San Ginés.

Palabras Clave: hibridación genérica; Lo fingido verdadero; unidad artística; comedia de santos; San Ginés; metateatro; Diocleciano.

Abstract: Hybridization of Genres and Artistic Unity in the Hagiographic Comedy: the Process of Hybridization in Lo fingido verdadero.

This article explores the phenomenon of hybridization of dramatic genres in a remarkable hagiographic play by Lope de Vega, Lo fingido verdadero. It studies how numerous elements of a heterogeneous nature are integrated into it, within a mobile dramatic structure in which features of historical drama, cloak-and-sword comedy, comedia de enredo, tragedy and comedia de santos are combined. Lope manages to confer artistic unity to the set of characters and events of different genres through an articulating theme of the three acts (the metaphor of the theatrum mundi) the game of opposition between two main characters, and a network of recurrences, symmetries, contrasts and symbols. The relation of the work with its sources and the comparison with other Hagiographic comedies by Lope or with other Spanish dramas on the figure of Saint-Genesius are taken into account.

KEYwORDs: Hybridization of genres; Lo fingido verdadero; Artistic unity; Hagiographic comedy; Saint-Genesius; Metatheatre; Diocletian. 
HIBRIDACIÓN O INTERFERENCIA DE LOS GÉNEROS ${ }^{1}$

$\mathrm{D}$ urante el siglo XVII, al responder a las obligaciones comerciales de la escritura para el teatro, los poetas quizás llegaran a hacerlo en ocasiones de un modo rutinario y mecánico, pero tal actitud no podía prolongarse en el tiempo sin causar enfado. Si realmente se quiere mantener vivo un arte nuevo de hacer comedias que atraiga al público a lo largo de los años y que mantenga el éxito económico, corresponde al ingenio creador salir de los límites de lo esperable y, por ejemplo, explorar las posibilidades combinatorias de diferentes modalidades dramáticas hasta forzar sus límites, en una acción que podemos llamar "juego" o "experimentación” que mantenga abierto el interés de los espectadores.

Como es de suponer, de un modo ejemplar puede apreciarse esto en Lope de Vega:

si bien es cierto que el discurso dramático de Lope, para ceñirnos a él, se despliega con coherencia estética e ideológica y a menudo es fiel a unos esquemas previos de composición, no es menos cierto que de tiempo en tiempo, aquí y allá, en esta obra o en la otra, tiende a desestructurarse, a explorar vías inéditas, a hurgar en las posibilidades de lo heterogéneo, de las mezclas sorprendentes, de los casos excéntricos. ${ }^{2}$ (Oleza y Antonucci 2013:723)

Lo que Joan Oleza dice atinadamente sobre la trayectoria dramática de Lope de Vega puede extenderse de forma general a la consideración de otros poetas, los más creativos, del siglo XVII, que se complacen a veces en desafiar o en jugar con las expectativas del público. La "mezcla", 3 "hibridación” o "contaminación de géne-

1. Retomo aquí, con alguna variación, parte de la introducción a un reciente artículo (Rubiera 2021) con el que se comparte el mismo planteamiento inicial.

2. García Reidy reflexionaba en la misma línea al subrayar «la continua vocación de experimentación que muestra el dramaturgo madrileño en el marco de cada uno de los subgéneros en los que se adentra, forzando con frecuencia los límites genéricos y planteando conflictos dramáticos similares desde ópticas diferentes» [2009:19].

3. Ténganse bien en cuenta estas palabras de Joan Oleza: «La mezcla como valor. La actitud de insumisión frente a las categorías heredadas, y la decisión de combinarlas y mezclarlas se extiende 
ros" tiene como resultado una ambigüedad que es lógico que produzca diferencia de opiniones según la perspectiva adoptada por cada crítico para su análisis, por lo que la clasificación genérica de ciertas comedias no es evidente y, por ello, las propuestas críticas pueden resultar variadas. Lo que parece claro es que no sería conveniente su inclusión en un género con un simple rótulo reductor y que hay que introducir otras consideraciones que traten de dar la mayor precisión posible al respecto.

En este sentido, creo que los responsables de la plataforma Calderón digital aciertan plenamente cuando al elaborar sus fichas para la base de datos presentan a continuación de una "propuesta de adscripción genérica» una «propuesta de adscripción genérica secundaria» y un lugar para «notas» complementarias que acaben de matizar, si es necesario, una cuestión que a veces es tan compleja como sutil y, por supuesto, discutible. ${ }^{4}$ Fausta Antonucci [2018:88-90] explica con claridad los presupuestos metodológicos en los que se asienta esta base de datos y precisa cómo simplifica en su mapa conceptual el modelo de los «esquemas conceptuales» utilizado por ARTELOPE, que, a mi modo de ver, había llegado a análisis genéricos tan finos como el propuesto para El villano en su rincón. ${ }^{5}$ Precisamente utilizando ARTELOPE como herramienta de investigación, Antonucci llegaba hace algunos años a la conclusión de que se podía «sustentar y desarrollar la hipótesis de una consistente presencia de formas variadas de hibridación genérica en la dramaturgia de Lope» y de que «se trata de un fenómeno que no se concentra en un periodo determinado de la producción del dramaturgo, sino que interesa todas las fases de su actividad dramática» [2013:156]. Por lo tanto, dado el enorme caudal del corpus teatral lopesco, es conveniente dedicar estudios individuales a obras bien significativas para observar de qué modo particular y diferenciado tiene lugar la hibridez genérica, entendida como resultado o fruto de un proceso de hibridación en el laboratorio de escritura de Lope.

\footnotetext{
a toda la poética de la comedia nueva, hasta el punto de devenir de precepto específico en valor del nuevo sistema dramático» (Oleza y Antonucci 2013:696).

4. Por ejemplo, ver en la base de datos las entradas para El príncipe constante, La devoción de la cruz o Argenis y Poliarco: <http://calderondigital.unibo.it/>. Consulta del 19 de mayo de 2021.

5. Ver la entrada correspondiente en la base de datos: <https://artelope.uv.es/>. Consulta del 19 de mayo de 2021.
} 


\section{UNA COMEDIA HAGIOGRÁFICA: LO FINGIDO VERDADERO}

Hay géneros potencialmente más híbridos que otros, como la comedia religiosa y más en particular la comedia hagiográfica, que por su propia condición admiten más fácilmente la posibilidad de acoger rasgos, lances y convenciones de otros géneros, es decir, «elementos de distinta naturaleza». ${ }^{6} \mathrm{~A}$ propósito de este tipo de comedias escribía Elisa Aragone Terni: [1971:43]:

Sta di fatto che un lavoro di tale genere, in quel tempo, non poteva prescindere né dalla mescolanza di elementi eterogenei, né dalle discussioni teologiche accanto a scene d'amore, né dalla convivenza di personaggi sacri e profani, né dalle — per noi— inverosimiglianze ed incongruenze. ${ }^{7}$

Entre las comedias lopescas habitualmente conocidas como "de santos", ocupa un lugar especial Lo fingido verdadero, «tragicomedia de la vida y martirio de San Ginés, representante» (ed. L. Giuliani, p. 759), tal como se refiere a ella Lope en su dedicatoria a F. Gabriel Téllez, en la Decimasexta Parte publicada en 1621. El más reciente editor de la comedia la ha calificado como «aparente híbrido entre drama histórico y comedia de santos» (ed. L. Giuliani, p. 737) у a ella se prestará atención en las próximas páginas. ${ }^{8}$ Una vez caracterizada esta supuesta hibridez de la obra, nos preguntaremos si afecta a su equilibrio estructural y de qué modo Lope trata de dar unidad artística a la pieza mediante diferentes recursos que permiten combinar con coherencia elementos de distinta naturaleza.

6. Retomo aquí la simple definición del Diccionario de la lengua española (RAE, 2020): «Hibridez: Cualidad de híbrido (producto de elementos de distinta naturaleza)».

7. No parece necesario aportar más citas que abunden en este sentido. Baste con referirme a la afirmación reciente de J. Dann Cazés tras un repaso a la bibliografía sobre las comedias de santos: «Pero a pesar de las dificultades para hablar de la comedia hagiográfica y para señalar sus rasgos genéricos, es un hecho que este teatro ha estado siempre identificado como un conjunto de piezas bien diferenciado. En todo caso, la crítica actual concluye que, si este género se caracteriza por algo, es por su heterogeneidad y su hibridez» [2015:42-43].

8. Todas las citas de la comedia se harán por la edición de Giuliani. 


\section{UNA OBSERVACIÓN PRELIMINAR}

No se sabe para qué fiesta religiosa se compuso Lo fingido verdadero, ni si es fruto de un encargo individual o de una corporación municipal o eclesiástica, pues no hay datos en torno a la representación de esta comedia. Probablemente escrita hacia 1608, su texto se conoce únicamente por la impresión de 1621, tan importante y tan peculiar en la historia de las Partes de Lope. ${ }^{9}$ Dada esta condición de testimonio único, habría que tener siempre en mente la posibilidad de que nos encontremos ante un texto que difiera del originalmente ideado por Lope de Vega para ser representado durante una determinada festividad. No se puede desatender el hecho de que no sabemos realmente a qué estadio responde el texto impreso en la Parte XVI, pues se conocen suficientes casos - muy diferentes entre sí, pero muy significativos- de otras comedias lopescas, religiosas o no (La dama boba, La buena guarda, Barlaán y Josafat, etc. $)^{10}$ con diferencias notables entre el autógrafo lopesco y una impresión en una Parte de Lope o a nombre de Lope. ${ }^{11}$ No se olvide lo que el propio Fénix señalaba en 1621, en alusión a sus comedias de la Parte XV: que «él hace lo que puede por ellas; mas puede poco, que las ocupaciones de otras cosas no le dan lugar a corregirlas como quisiera, que reducirlas a su primera forma es imposible; pero tiene por menos mal que salgan de su casa que no de las ajenas» (Vega, Decimaquinta Parte, s.p.). ${ }^{12}$ Por ello, parece prudente cuestionarse si el texto de Lo fingido verdadero publicado en la Parte XVI responde a la «primera forma» de la comedia.

9. Ver al respecto la introducción de Florence d'Artois y Luigi Giuliani [2017] a la edición completa de esta Parte.

10. En cuanto a Barlaán y Josafat, ver la excelente edición de Daniele Crivellari, quien en su introducción abunda en explicaciones sobre el manuscrito autógrafo de Lope y sobre «avatares de la comedia entre reelaboraciones, huellas y representaciones» [2021:52].

11. En la Parte XVI, para la primera comedia impresa en el volumen, El premio de la hermosura, Florence d'Artois y Héctor Ruiz llegan a proponer la existencia de tres versiones distintas, aunque solo se haya conservado el texto impreso en la Parte. Reconocen, sin embargo, «que sabemos que suele haber una relativa estabilidad entre la versión de una comedia manuscrita y la versión publicada en las Partes» [2017:66]. Respecto a Lo fingido verdadero, Dixon piensa que para la edición de la Parte el manuscrito que se empleó «fue afortunadamente el original de Lope o, al menos, una copia no muy distinta de él» [2013:176], mientras Cattaneo cree que «lo stato non soddisfacente della Parte XVI induce comunque a ritenere che il testo di Lope abbia subito un certo deterioramento» [1992:39] .

12. Para otras citas de interés, del propio Lope, en el mismo sentido, ver Dixon [2013b:108-109]. 


\section{UN CAMBIO EN LA CONSIDERACIÓN CRÍTICA}

Cuando en 1980 Gustavo Umpierre publica su artículo sobre Lo fingido verdadero, se sorprende de la poca atención crítica recibida por esta «comedia metafísica» de gran mérito: «Resulta penoso decir hoy día que el único estudio substancial que existe de esta obra lo sigue siendo el de Menéndez Pelayo en sus Estudios sobre el Teatro de Lope de Vega, a finales del siglo XIX» [1980:161-162]. Lo cierto es que, por ejemplo, Delfín L. Garasa [1960] y Elisa Aragone Terni [1971] le habían dedicado cierta atención en el marco de sendas obras que trataban del teatro hagiográfico o que Orozco [1968] la tuvo en cuenta de modo pasajero en su penetrante estudio sobre la teatralidad del Barroco, pero junto a ellos, las observaciones anteriores de Vossler [1932], de Valbuena Prat [1956], de Marín [1958] o de Trueblood [1964] eran más bien excepciones. Sin embargo, con el tiempo esta comedia ha ido creciendo en importancia y ha sido valorada extraordinariamente por tan buenos conocedores del conjunto de la obra lopesca como D. Castillejo [1984] o V. Dixon [2013a]. En este cambio de consideración jugó un papel muy importante la publicación en 1963 de Metatheatre, libro de L. Abel que abrió en los estudios de teatro occidental un nuevo camino, controvertido pero muy fructífero, al explorar con una perspectiva novedosa y de un modo diferente lo que sí había sido muy ampliamente estudiado en torno a la metáfora de the world as a stage o del theatrum mundi. ${ }^{13}$ Muy pronto esta vía de investigación sobre la metateatralidad fue cultivada en el ámbito del teatro español, particularmente el de los siglos XVI y xvII, dando lugar con el paso de los años a numerosísimos trabajos académicos. ${ }^{14}$ Como era lógico pensar, en ellos habría de tener un lugar especial Lo fingido verdadero, junto a otras joyas de lo metateatral en el Siglo de Oro, como el entremés cervantino El retablo de las maravillas y el auto calderoniano El gran teatro del mundo. En 1977, Susan L. Fischer publicaba desde este punto de vista un excelente artículo — sobre la dramatización de la experiencia teatral— que no pareció conocer Umpierre, y por esa época empezaba sus

13. Se contaba por entonces con estudios que trataban el tema con rigor, como los de Curtius [1955], Jacquot [1957] o Vilanova [1950].

14. Un buen ejemplo que reúne trabajos de mucho interés es el número $\mathrm{V}$ de la revista Teatro de palabras [2011] dedicado monográficamente a la metateatralidad, en el que los artículos de G. Serés y de M. Zugasti dedican una parte a Lo fingido verdadero. El artículo introductorio de Hermenegildo, Rubiera y Serrano sirve de útil contextualización del término "metateatro" aplicado a los estudios del Siglo de Oro. 
estudios sobre esta peculiar tragicomedia lopesca Maria Teresa Cattaneo, una de sus mejores conocedoras..$^{15}$ De 1981 data también un trabajo de Duncan W. Moir que contrasta el arte de actuación de Ginés (y el de Diocleciano) con reflexiones extraídas de Diderot y de Chaliapin. Es a partir de este momento (1977-1981) cuando la obra comienza a ser estudiada en profundidad y valorada por algunos como «one of Lope's best plays» (Moir 1981:33), «un prodigio de comunicación teatral barroca» (Palomo 1987:98), «la más teatral de todas [sus comedias], al mismo tiempo muy barroca y muy moderna» (Dixon 2013a:159).

Desde entonces creo que lo mucho que se ha escrito en torno a Lo fingido verdadero apunta a estas orientaciones principales, algunas de las cuales se combinan a veces en un mismo trabajo: 1) los estudios que prestan especial atención a la cuestión de la metateatralidad y los niveles de ficción en la obra; 2) los que tratan de entender los principios constructivos de la comedia en su conjunto y como obra hagiográfica; 3) los que se dedican a alguno de sus aspectos compositivos, siempre difícilmente separables de los problemas de la ficcionalidad y de la consideración del mundo como un escenario; 4) aquellos otros que la ponen en comparación con obras dramáticas que la han tenido como fuente o presentan fuertes analogías con ella; 5) los que consideran aspectos de estética y de teoría teatral vinculados a la doctrina del Arte nuevo de hacer comedias, escrita por el mismo tiempo que el drama. ${ }^{16}$

Nuevos DATOS SOBRE LAS FUENTES Y SOBRE UNA COMEDIA DESCONOCIDA EN TORNO A SAN GinÉS

En los últimos años se han revelado algunos nuevos datos y textos que habrá que tener en cuenta en futuras discusiones sobre Lo fingido verdadero. En primer lugar,

15. Su edición de Lo fingido verdadero es de 1992, pero en ella incluye como introducción su trabajo «Il teatro del mondo e il mondo del teatro. Lettura di Lo fingido verdadero di Lope de Vega», anotando: «Ripubblico, in occasione dell'edizione — sollecitata da un corso universitario - un mio 'antico' studio apparso, insieme ad altri saggi, in un'edizione limitata, Studi sul teatro spagnolo, nel 1979» (Cattaneo 1992:7).

16. La comedia es de una gran riqueza y complejidad, por lo que, como un verdadero clásico, sigue despertando interés desde nuevos enfoques críticos. El último que conozco es el de L. Pawlita [2019] que la analiza en el contexto del pensamiento escéptico de los siglos XVI y XVII en el capítulo «Aspects of Skepticism in the Genesius Plays by Lope de Vega and Jean de Rotrou». Profundiza así en una línea que había iniciado B. Simerka [2005], aunque disintiendo de ella en algunos puntos. 
se ha señalado mejor la posible fuente en que se basa lo relativo a la historia de San Ginés, que hasta hace poco se venía identificando con el Flos sanctorum de Pedro de Ribadeneyra, según lo propuesto por Menéndez y Pelayo en 1894. En un artículo de 2016 orientaba yo a la crítica hacia un Flos sanctorum anterior, el de Alonso de Villegas, que contiene en su formulación detalles y matices de gran interés. ${ }^{17}$ En una investigación posterior (Rubiera 2020) he apuntado al Fructus sanctorum —que es la quinta parte del Flos sanctorum de A. de Villegas publicado en 1594-, como otro texto que incluye nuevas informaciones de provecho para interpretar la figura de Ginés. Además, puede añadirse ahora que el breve relato sobre la vida y martirio de este santo debió de circular desde la primera edición del Flos sanctorum de Villegas, pues - a falta de poder comprobarse en un ejemplar de esa primera edición impresa- así aparece recogido en el original de imprenta conservado en la Real Biblioteca de Madrid (II/1812), con fecha de 1578, año de esa primera edición.

La segunda novedad tiene que ver con la aparición de una comedia sobre San Ginés, desconocida hasta ahora, anterior a la de Lope de Vega, con la que puede contrastarse, por ejemplo, para observar las diferencias en el modo de componerse la fábula en relación con la fuente o para hacer comparaciones en la manera de tratar la cuestión metateatral, siendo esta obra uno de los ejemplos más tempranos y desarrollados del «teatro en el teatro» en Europa. La Comedia de San Ginés es anónima, probablemente fue compuesta en la primera mitad de la década de los noventa del siglo xvi y quizás fuera representada en el entorno de la Corte de Alba, por lo que es posible que el propio Lope la hubiera conocido. ${ }^{18}$

En tercer lugar, no a partir de datos externos sino de un minucioso estudio interno del texto, he planteado la posibilidad de que Lo fingido verdadero se hubie-

17. A partir de esta sugerencia, en el prólogo a su edición de Lo fingido verdadero Giuliani reproduce el texto de Villegas sobre «La vida de S. Ginés, representante, mártir» [2017:740-743]. En mi artículo de 2016 remitía yo a la considerada como primera parte del Flos sanctorum (Flos Sanctorum, y Historia general, de la vida y hechos de Jesucristo, Dios y Señor nuestro, y de todos los santos de que reza y hace fiesta la Iglesia católica [...],1591); en otro de 2020 señalo una edición anterior, la de 1588.

18. En colaboración con A. García Reidy preparo actualmente la edición anotada de esta comedia a partir del manuscrito 14644 de la Biblioteca Nacional de España. En el Congreso de la Asociación Internacional «Siglo de Oro» (Neuchâtel, 3 de noviembre de 2020), presentamos en sendas comunicaciones los principales rasgos de este drama. Los títulos de las comunicaciones fueron «El manuscrito anónimo de la Comedia de San Ginés: ¿un antecedente de Lo fingido verdadero?» (J. Rubiera) y «La anónima Comedia de San Ginés: un drama hagiográfico de la primera etapa de la Comedia Nueva» (A. García-Reidy). 
ra compuesto para ser representada en el marco festivo de Corpus Christi (Rubiera, 2016), hipótesis sobre la que volveré en el presente artículo.

\section{LO FINGIDO VERDADERO, ¿UNA COMEDIA DE SANTOS?}

Parece evidente que para Lo fingido verdadero la simple denominación de comedia de santos o comedia hagiográfica no es satisfactoria, como señalan muchos de los críticos que la han examinado. Dixon piensa que «no es más que parcialmente otra comedia de santos», que «ha sido un error de la crítica encasillarla como tal» y que «su forma y contenido son más complejos y de alcance mucho más amplio de lo que pudiera sugerirnos semejante designación» [2013a:160]. Por esta razón, se avanzan a veces nuevas denominaciones en un intento de observarla y comprenderla mejor desde otro punto de vista. Así hace, por ejemplo, G. Umpierre al proponer el rubro más general de «comedia metafísica» a partir del cual «quizá podamos descubrir una unidad más abarcadora que nos ayude a definir nuevamente la estructura temática y formal de la obra» [1980:163] o como sugiere J.V. Bryans al señalar «la combinación de dos sub-géneros», el de la «comedia de tiranos y el de la «comedia de mártires», lo que propiciaría «una rica experiencia teatral» en la que se comparan «las actitudes y el mundo de los paganos con las actitudes y el mundo de los cristianos» [1985:133].

Maria Teresa Cattaneo se refirió a Lo fingido verdadero como una «anomala comedia de santos» [2008:6]. De modo general, podría decirse que la anomalía reside en que a primera vista el carácter religioso propio de una obra hagiográfica se contamina demasiado de acciones y de elementos profanos que parecen más acordes con otros géneros, de ahí que pueda hablarse de hibridación. De este modo, la acción dramática en torno a su personaje principal — Ginés, el actor que se convertirá en mártir cristiano- se vería desequilibrada por la importancia de la acción en torno a la figura de Diocleciano, sobre todo en un primer acto en que este adquiere carácter protagonista al mostrar su ascenso al poder imperial desde su posición de humilde soldado, con el fondo de una turbulenta fábula de historia romana en la que mueren violentamente cuatro personajes. El segundo acto muestra a Ginés envuelto en sus preocupaciones sentimentales hacia una actriz de su compañía e introduce la representación de una comedia de amor y celos llevada a cabo por Ginés y su troupe ante Diocleciano, sin que acabe por aparecer aún el motivo cristiano 
devoto. Es decir, la acción de carácter religioso se retrasa demasiado hasta el acto tercero, en que tiene lugar el súbito golpe de gracia divina que lleva a la conversión de Ginés - durante un ensayo y durante una nueva representación ante Diocleciano-y su martirio. Además, en apariencia al menos, el tema que aparece y reaparece desde el primer acto al tercero - dando coherencia al conjunto- no sería un tema estrictamente religioso, sino el del «mundo como teatro», con numerosas reflexiones y alusiones complementarias al «mundo del teatro» (modos de escribir y representar comedias, métodos de actuación, composición de las compañías, etc.).

Si bien algunos especialistas han apuntado a la «promiscuidad de elementos heterogéneos» como factor que en general «ha hecho de la comedia de santos una especie extraña y desconcertante» (Garasa 1960:6), es muy fuerte el contraste entre Lo fingido verdadero y otras comedias de santos del propio Lope que se ajustarían mejor a lo esperable de una comedia religiosa «típica». Veamos rápidamente dos ejemplos significativos. La reconocida como primera de sus comedias hagiográficas, la dedicada a San Segundo en 1594, comienza con una discusión teológica entre Segundo, Torcato e Indalecio hasta la llegada de Diego (el apóstol Santiago), que viene platicando con Eufrasio y Teodoro sobre Cristo y su llegada al mundo anunciada por los profetas. Habla de la Anunciación de la Virgen, de la Encarnación y de cómo la Virgen le mandó «venir a España». Su actitud y sus santas palabras son suficientes para que Segundo decida convertirse, cuando no han transcurrido aún ni trescientos versos desde el comienzo de la comedia. Puede apreciarse aquí el cariz religioso inequívoco que se confiere a la obra desde el mismo comienzo, sobre un fondo histórico muy poco perfilado.

Una comedia muy apropiada para hacer comparaciones significativas con $L o$ fingido verdadero es Los locos por el cielo, que trata de la conversión y muerte de Santa Domna y de San Indes, historia también basada en el Flos sanctorum de Alonso de Villegas. Comparten estas dos obras un momento histórico muy próximo, durante la persecución de los cristianos en el Imperio romano, pues si en Lo fingido verdadero la acción es en época de Diocleciano, Los locos por el cielo transcurre poco después, en la de Maximiano (quien, además, aparece como personaje secundario en Lo fingido verdadero). Sin embargo, desde los primeros versos del acto primero se muestra con claridad una acción centrada en Maximiano como agente cruel de la persecución y muy rápidamente aparece la figura protagonista de Domna, que a mitad de la jornada ya habrá sufrido su conversión y habrá sido bautizada, siendo 
inmediatamente perseguida y encarcelada junto a Indes, que también ha decidido hacerse cristiano. En ese primer acto ya tienen lugar varias intervenciones angélicas y se produce un milagro (con la aparición sobrenatural de una mesa con panecillos y platos de miel), todo ello propio del efectismo edificante de una comedia que desde su comienzo muestra abiertamente sus cartas devotas. En la tercera jornada se introduce un juego metateatral, pero se hace mediante una representación en el marco de una fiesta de Navidad, un auto del Nacimiento, es decir, hasta este elemento metateatral aparece teñido debidamente de clara religiosidad cristiana.

Es lógico que frente a comedias de santos de este tenor sorprenda o extrañe la composición de Lo fingido verdadero y que se hayan hecho numerosas propuestas que traten de mostrar sus principios estructurales. La heterogeneidad de elementos y de acciones procedentes de diversos géneros responde, como es bien sabido, al ideal de «variedad» que se encuentra en el núcleo generador del arte de Lope, tal como él mismo expuso. Pero cuando se extrema la variedad siempre se corre el riesgo de la dispersión, perjudicando quizás la percepción de la obra en su unidad y en su equilibrio, lo que es considerado como un defecto. Como bien resume Giuliani [2017:746]:

ya desde las observaciones de Menéndez Pelayo se ha insinuado la idea de que Lo fingido verdadero es una obra desequilibrada $\mathrm{y}$, por lo tanto, mal estructurada por Lope. De ahí los intentos de descubrir los hilos, la figura en el tapiz que dé razón de la unidad de la obra, que pasa por la constatación de la existencia de una estructura tripartita tanto en el conjunto de la pieza como dentro de cada acto. Dicha tripartición respondería a la caracterización de cada uno de los tres actos según modelos de géneros distintos (el primer acto sería un drama histórico, el segundo una comedia de capa y espada, y el tercero una comedia de santos).

Dicho así, sin embargo, parecería que se trata de una yuxtaposición, pero diferentes acercamientos críticos han mostrado el modo de articularse con coherencia las tres jornadas, hasta poder afirmarse que «en realidad, el drama tiene una construcción magistral» (Wilson y Moir 1998:113) o que es «il risultato di una intenzionale e rigorosa costruzione che privilegia una struttura ternaria e simmetrica». ${ }^{19}$

19. Sobre Lo fingido verdadero se han escrito varios ensayos que tratan de explicar a partir de finos análisis los hilos con los que está elaborado coherentemente el texto de la tragicomedia, destacando los trabajos de Umpierre, Palomo, Cattaneo, Canonica, Dixon y d'Artois. Me refiero a algunos de ellos aquí para lo que me parece pertinente subrayar ahora. Particularmente, muy sugerente y 
La hibridez genérica de esta "sorta di trittico» (Cattaneo 1992:25) no solo se aprecia en el conjunto de la obra, sino dentro de un mismo acto, particularmente en el primero, que no puede ser identificado sin más con un «drama histórico». Se divide claramente en tres partes o bloques de acción: ${ }^{20}$ en la primera se presenta a Diocleciano y a sus compañeros durante una campaña militar en Mesopotamia, en la que morirá fulminado por un rayo el César Aurelio Caro, tras desafiar a los dioses; en la segunda parte tiene lugar el asesinato del César Carino - hijo de Aurelio— en las calles de Roma, durante una ronda nocturna, llena de variados lances y diálogos; en la tercera, cuando el ejército romano está de vuelta en la península itálica no muy lejos de Roma, se muestra el crimen de dos candidatos a la jefatura del imperio (el cónsul Numeriano - hijo del César Aurelio- y el cónsul Apro) y la proclamación de Diocleciano como emperador por parte de las tropas.

Se aprecia la distinta naturaleza dramática de esta parte segunda del acto primero, que contrasta con las otras dos partes que la abrazan estructuralmente, aunque comparta con ellas el crimen de un candidato al Imperio, que va despejando el camino de Diocleciano por acción de la Fortuna. Es una escena nocturna en espacio urbano en la que el disoluto Carino deambula por la ciudad con su criado Celio y con su amante, Rosarda, disfrazada de hombre. Comienza, pues, con un tono y un ambiente muy diferentes de la acción anterior en Mesopotamia. Hay toques de ingeniosa graciosidad por parte del criado, se introduce una conversación sobre el mundo como teatro y los hombres como personajes, los tres se plantan delante de la casa de unos actores y se hace la presentación de Ginés, que dialoga con Carino, declarándosele representante oficial del César. La aparición del cónsul Lelio dará un vuelco a la acción, pues con la ayuda de tres soldados asesina a Carino por un

agudo me parece el artículo de d'Artois, quien parte de considerar que «Lo fingido verdadero sigue una estructura que casi podríamos llamar en cascada o en fuga» [2005:181] hasta llegar a explicar de modo muy convincente que esta comedia «es un ejemplo de perfecta adecuación de una forma estética a una postura metafísica» [2005:188].

20. Mientras la segunda parte (vv. 307-666) y la tercera (vv. 667-988) se corresponden estrictamente con sendos cuadros, la primera parte consta de dos cuadros (vv. 1-192; vv. 193-306) que comparten la misma localización y están articulados principalmente por el ruido de la tormenta: Diocleciano y sus compañeros comentan la terrible tempestad que comienza y dejan el tablado vacío unos segundos, dando lugar a la entrada del César Aurelio, solo. Tras el rayo que lo fulmina, entran de nuevo en escena Diocleciano y soldados, junto a Numeriano y Apro, y encuentran su cuerpo. El modo de articularse estos dos cuadros merecería comentario detenido por el uso magistral de la ironía en la última intervención de Diocleciano antes de irse de escena (vv. 191-192): «¿Cuándo has visto emperador / romano muerto de rayo?». 
motivo de honor. Carino reconoce antes de morir que se acaba en tragedia la figura de Rey o César que representaba, y que otro vendrá a vestir sus ropas para que continúe su papel en la representación de la vida. En unos trescientos cincuenta versos tiene lugar una mini tragicomedia, en la que se mezclan lances propios de comedia de capa y espada con otros propios de drama o tragedia de honor, que termina con el magnicidio del tirano.

\section{UNIDAD EN LA VARIEDAD}

Al hilo de esta intervención final de Carino, puede afirmarse que el modo de entender la unidad artística de Lo fingido verdadero pasa, en primer lugar, por reconocer que el tema de la metáfora del theatrum mundi vertebra la comedia desde el primer acto al tercero en un juego que puede entenderse muy bien por analogía con el mundo musical o el pictórico, como hace Dixon [2013a:168]:

Las múltiples historias que se desarrollan ante este telón de fondo conceptual son variaciones análogas sobre un mismo tema. Repetidamente las ficciones vividas por sus personajes - los papeles que se crean y desempeñan — los llevan a la realidad; pasan de las burlas a las veras, de lo fingido a lo verdadero. Los tres actos de la obra son como los distintos movimientos de una pieza musical, o las hojas complementarias de un tríptico pintado.

En segundo lugar, su unidad se entiende mejor cuando se constata que la figura protagonista de la comedia, Ginés, no ocupa un puesto central y único, sino que está construida en oposición a la figura de Diocleciano. Nótese que la comedia anónima, anterior a Lope, sobre la figura del santo actor llevaba por título Comedia de San Ginés, mientras que Lope la titula sin referencia explícita al santo, bien como Lo fingido verdadero, bien como «El mejor representante», según aparece en la lista de El peregrino en su patria de 1618. La «sconcertante mobilità de la struttura» y su «policentrismo», que tan bien señaló Cattaneo [1992:23], tienen que ver con este punto fundamental del doble protagonismo en contraste. En el primer acto, la comedia pone el foco en Diocleciano desde las primeras escenas, y durante el desarrollo de los acontecimientos de su historia hace aparecer, de perfil o desenfocado aún, el personaje de Ginés en Roma, alejado de Diocleciano todavía. El segundo acto tiene ya a 
Ginés en el centro, compartiendo protagonismo con Diocleciano y sus cuitas, y produciéndose la primera representación de la compañía de Ginés ante el César. La tercera jornada presenta al comienzo la misma relación de protagonismo doble, pero tras el bautismo en escena de Ginés, durante la segunda representación, y la condena del airado Diocleciano, este se difumina y desaparece de la obra, dejando solo a Ginés en el tramo final, empalado, con el foco sobre su figura patética en el martirio.

Al preparar para la escena una composición sobre la vida y muerte de San Ginés, Lope toma una serie de decisiones que marcan la comedia con rasgos que la diferencian claramente de otras que en principio pertenecen al mismo género. ${ }^{21}$ Una decisión fundamental es la de hacer que el personaje de Diocleciano cobre protagonismo desde el principio y sirva de contraste al de Ginés, lo que permite a su vez contraponer la visión del mundo pagano - regida por presagios, por la Fortuna, y por hombres adorados como dioses - a la visión del mundo cristiano, providencialmente regida por Dios. Es algo ya señalado por la crítica y puesto en relación con los dos tipos de fuente a los que recurre Lope, pues al uso de un Flos sanctorum como base para la vida de Ginés añade una historia de Roma (la Historia imperial y cesárea de P. Mexía) para la de Diocleciano, «fuentes que separadamente determinaron la estructura de trama doble que Lope dio a la comedia» (Marín 1958:93). ${ }^{22}$ Sin embargo, pueden añadirse nuevas reflexiones y matices al respecto.

Al remitir al Fructus sanctorum de Alonso de Villegas como posible fuente, no solo se ilumina la posible inspiración para el título de la comedia. ${ }^{23}$ De modo muy significativo, Villegas [1594:333v-334r] recuerda la historia de Ginés como un caso para ilustrar el discurso 53, «De mudanza de vida» (ejemplo 14). Junto a él muestra otros cuarenta y nueve casos de tres procedencias distintas: bíblica, de asunto cris-

21. Dos decisiones «negativas», también fundamentales, la orientan por rumbos bien distintos de otras comedias religiosas: 1) no introduce figura de demonio; 2) no dota de figura de gracioso a la obra, ni de elementos cómicos de importancia.

22. Así lo señalan numerosos críticos, desde Menéndez y Pelayo [1894] a Giuliani [2017]. Particularmente claro era Umpierre en su planteamiento al señalar que «las dos acciones principales, político-militar y dramático-lírica, giran alrededor de las dos figuras centrales, Diocleciano y Ginés: Mundo pagano antiguo y mundo cristiano primitivo, vistos por la sensibilidad contrarreformista» [1980:190-191]. Me parece muy significativo que la última traducción al inglés de Lo fingido verdadero lleve por título primero The Actor and the Emperor, poniendo el foco en la pareja protagonista.

23. "Muy significativamente terminaba el ejemplo 14 con unas palabras que se referían al santo de esta manera: "fue verdadero mártir el que antes en sus farsas parecía fingido cristiano". Por ello es verosímil pensar que Lope de Vega lo tendría en mente al idear el título de la comedia que compuso sobre San Ginés, Lo fingido verdadero» (Rubiera 2020:665). 
tiano o de asunto pagano o «extranjero», como él dice. Villegas se refiere a que «entre muchos que mudaron la vida, y de estado bajo subieron a alto», se encontraron varios reyes y emperadores, y entre ellos «a Diocleciano, emperador de Roma, ya le hacen hijo de escribano, ya de librero». ${ }^{24}$ En busca de explicación para la mudanza de vida de Diocleciano, encuentra Lope fundamento histórico-legendario en la obra de Mexía, de la que toma el elemento dramático que más va a desarrollar, en torno a la profecía de Camila a Diocleciano, cuando era un simple soldado: «Tú serás César romano / en matando un jabalí» (vv. 159-160).

Es importante notar que Lope decide centrarse en la cara más amable de Diocleciano, ya que tiene este emperador romano otra cara terrible, al ser uno de los más crueles y sanguinarios perseguidores de los cristianos, cara a la que se refiere también Villegas en otros pasajes del Fructus. ${ }^{25}$ Lope toma un rumbo diferente al que había seguido con la figura de Maximiano en Los locos por el cielo, al que hemos aludido antes, porque no es el de tirano / mártir el tipo de contraste que le interesa privilegiar ahora, sino el de la visión del mundo pagano frente a la visión del mundo cristiano en relación con la «mudanza de vida», presentadas en fuerte contraposición a través de Ginés y Diocleciano.

\section{TRES ELEMENTOS EXTRAÑOS EN LA COMPOSICIÓN}

DE LO FINGIDO VERDADERO COMO POEMA DRAMÁTICO

El texto dramático de Lo fingido verdadero, tal como se nos ha transmitido, contiene algunos fragmentos de rara integración en la acción dramática, que en principio no parecen poder explicarse por las dos consideraciones aducidas en el apartado anterior (tríptico a modo de tema con variaciones; protagonismo dual). Contribuyen a la impresión de Lo fingido verdadero como una obra «che accumula, per ansia di varietà di contenuti, [...] materiali diversi e non sempre omogenei» (Cattaneo 1992:23). ¿Por qué habrán sido insertados en el poema dramático? Efectivamente, tras el análisis

24. En Lo fingido verdadero Lope hace decir a Diocleciano que es hijo de un esclavo (v. 909).

25. Por ejemplo, en el «Discurso vigésimo primo. De crueldad», se dice: «Juntamente con Maximiano era emperador Diocleciano, el cual, en tanto se mostró cruel contra los cristianos, que excedió a otros en crueldad cuanto excede el león al cordero en ferocidad. Y con esto, quien quisiese particularizar las crueldades que este infernal hombre y otros que le imitaron hicieron contra cristianos, sería contar las estrellas del Cielo y las arenas del mar» (Villegas, f. 116r). Sigue una lista de horrores. 
detenido de la comedia, en tres momentos principales saltan a la vista pasajes de notable valor poético que, sin embargo, causan extrañeza - por motivos diferentesy hacen cuestionarse sobre su función en la obra. Se trata de una letrilla, de un romance y de un soneto, ${ }^{26}$ que van a permitir entender desde otro punto de vista el fenómeno de la hibridación, así como profundizar en ciertas peculiaridades de la pieza.

Uno de los modos de proporcionar cohesión a un conjunto heterogéneo de elementos es la introducción de simetrías y de correspondencias, que confieren armonía a lo que en principio podría parecer acumulación disonante. En general, es un recurso propio del arte barroco, y tiene gran rendimiento en esta como en otras comedias lopescas. Por ejemplo, en el segundo y en el tercer acto de Lo fingido verdadero se introducen sendas representaciones de Ginés y su compañía ante Diocleciano y su corte. Estas representaciones soportan como dos columnas paralelas la construcción dramática y espectacular de las dos jornadas, constituyendo los dos momentos clave de «teatro en el teatro». En ambas se sigue esta estructura, entreverada con comentarios de los espectadores: introducción musical cantada, loa, comedia (interrumpida por un hecho inesperado), interacción entre público y actores. Por supuesto, Lope le confiere variedad al mismo molde, por ejemplo, al hacer que Ginés diga la primera loa y que sea Marcela quien recite la segunda, o al contrastar el carácter de comedia de amor y celos de la primera representación con el carácter religioso, que se resuelve en «tragedia», ${ }^{27}$ de la segunda, «la del cristiano bautizado» (v. 2391). Sin embargo, puede apreciarse que en la estructura de la representación inserta en el segundo acto la sucesión de partes contiene una variante extraña e innecesaria desde el punto de vista dramático. «La Música» canta veinticuatro ver-

26. Con una esperable gran variedad métrica, Lo fingido verdadero consta de 3123 versos y no de 3507, como aún hoy puede leerse en la entrada correspondiente en la base de datos de ARTELOPE, que sigue lo indicado erróneamente por Morley y Bruerton [1968:326-327]. Es extraño que Dixon [2013a:178] no reparara en el error, pero sí lo hace Giuliani, aunque le «parece difícil imaginar a qué se debe la cifra total de 3507 versos» [2017:756]. La explicación es que en el texto de Morley y Bruerton, aparte de no contabilizarse correctamente el número de versos — que según sus propios datos deberían sumar estrofa por estrofa 3057-, se produce, además, un baile de cifras. En la sinopsis de versificación realizada por Giuliani deben corregirse los datos relativos al acto tercero [2017:755]: conviene señalar correctamente que entre los versos 2758-2849 se encuentra un pasaje en redondillas, sin computar por Giuliani. De igual modo, lo que aparece computado como un pasaje en quintillas (vv. 2980-3059) debe considerarse como décimas, por lo que en este sentido sí es adecuada la observación de Morley y Bruerton [1968:327] sobre el porcentaje tan alto de décimas para fecha tan temprana. Deben corregirse en consecuencia los datos y los cálculos en el «Resumen» métrico final de Giuliani [2017:755].

27. No se olvide que Camila, justo antes de que salga a cantar la Música en la segunda representación (tercer acto), dice: «Silencio, que comienza la tragedia» (v. 2601). 
sos de romance en honor de Diocleciano (vv. 1464-1489), después sale Ginés a decir su loa (vv.1490-1575), en humilde halago a la «divina, augusta y sacra presencia» (vv. 1550-1551) del Emperador y, seguidamente, tras un pequeño diálogo entre los espectadores, de nuevo salen «los Músicos» a cantar, en este caso una letrilla (vv. 1588-1617). ${ }^{28}$ Justo antes de que salgan, Diocleciano ha ordenado a Camila que vaya a llevarle un anillo a Ginés como premio por su loa. No hay acotación que lo señale, pero es evidente que ella debe irse de escena a cumplir el mandato. Tampoco hay acotación que la haga regresar y Camila no vuelve a tener intervención hablada en el resto del acto. Extraña decisión esta de separar a Camila en ese momento, sin más "justificación” que la de llevar el premio a Ginés.

Los Músicos comienzan entonces su canción dedicada a Lucinda, ${ }^{29}$ que la crítica ha señalado como un homenaje de Lope a su amante, la actriz Micaela de Luján, transformada en su obra poética como «Camila Lucinda». ${ }^{30}$ La canción, que imita una famosa composición de Góngora, tiene un carácter lírico y solo de modo general podría entenderse su función dramática en relación con el tono amoroso de la comedia intercalada que sigue, pero no tiene verdadera imbricación con ella. Esta segunda intervención musical, dirigida a una desconocida Lucinda, no es necesaria para la economía dramática, rompe el paralelo estructural con la representación del tercer acto, coincide con la desaparición injustificada del personaje de Camila y retrasa innecesariamente el comienzo de la larga comedia intercalada, que se prolongará durante casi cuatrocientos versos. ${ }^{31} \mathrm{Mi}$ hipótesis es que habría que entenderla posiblemente como la introducción de un elemento ajeno a la obra dramática de Lo fingido verdadero, pero importante para el poeta (Lope) desde un punto de

28. No es extraño por sí mismo que tras la loa vuelva a salir la Música a cantar antes de que comience la comedia, sino por los motivos que se aducen a continuación.

29. La composición comienza así: «No ser, Lucinda, tus bellas / niñas formalmente estrellas / bien puede ser; / pero que en su claridad / no tengan cierta deidad / no puede ser». Cattaneo la define como «sextilla paralela de pie quebrado» [1992:52], mientras Giuliani se refiere a ella como «serie de dos octosílabos en pareado con estribillo de pie quebrado (aab)» [2017:754].

30. Giuliani anuncia en la introducción a su edición un trabajo en preparación «sobre si incluir o no Lo fingido verdadero entre las piezas que Lope escribió para que se luciese su amante y en general sobre el empleo de los actores de la compañía en relación a la construcción del mecanismo del teatro en el teatro» [2017:738], que probablemente arroje luz sobre la cuestión aquí examinada.

31. La canción no es necesaria para separar la salida de escena de Ginés tras decir la loa y su entrada en escena de nuevo para representar en la comedia intercalada su papel de «Rufino», de galán, pues habría sido suficiente como transición el lapso con los comentarios del público y, quizás, una brevísima intervención instrumental. 
vista personal, por su probable relación con una actriz que interviene en el espectáculo. Es bella poesía, con poca justificación dramática, que encaja mal en el espectáculo —salvo el hecho siempre notable de proporcionar una dulce intervención músico-poética, confiriendo variedad con su tono lírico-, y parece un elemento heterogéneo, quizás añadido a posteriori para una representación determinada.

$\mathrm{El}$ segundo momento «extraño» a considerar se refiere a un largo romance dicho al comienzo del tercer acto (vv. 2139-2236) por un personaje secundario, Rutilio. Se trata de una relación, de esas que lucirían por extremo también en octavas, sobre las extrañas fieras que han traído al Emperador. Contiene, por ello, toda una serie de nombres peregrinos: leontocomos, cercopiteco, cinoprosopo, camelopardal, pathaga, catobleto, etc., que dan lugar, además, a descripciones de las raras especies. Por supuesto, con razón se han entendido como «fabuloso bestiario medieval» (Umpierre 1980:183) o como «versos a manera de barroca cornucopia zoológica» (Palomo 1987:86) que «crean un ambiente extraordinario y exótico» (Di Pinto 1999:212). Son, efectivamente, ejemplo de exuberancia barroca destinada a los oídos y a la imaginación del público. Son también versos escritos para el lucimiento del actor, un tour de force para el recitante, pero que hoy nos dejan indiferentes o pueden adaptarse para crear un efecto cómico. ${ }^{32}$ Bien es verdad que el ingenio de Lope logra posteriormente darle un sentido nuevo, cuando Camila le dice a Diocleciano que conoce una fiera mayor que todas estas: «Diocleciano ¿Y cómo se llama? / CAMila Amor.» (v. 2243). Al modo de esos sonetos que tras una abigarrada enumeración de elementos se rematan en un último endecasílabo esclarecedor («esto es amor, quien lo probó lo sabe», «y nada temí más que mis cuidados»), ${ }^{33}$ consigue Lope dotarle de sentido a una tirada del todo impertinente a la acción dramática, en aras del efecto sobre el público del espectáculo, sin que tenga relación alguna con este tercer acto en el que la religiosidad ocupará por fin el centro. ${ }^{34}$

32. Al pensar en un montaje moderno de la comedia, Dixon dice que suprimiría esta «larga lista (ciento dos versos de romance) de fieras fabulosas», aunque reconoce en nota que «es una cuestión de gustos; por ejemplo, una versión muy libre y humorística de esta lista fue uno de los éxitos del montaje londinense» de Lo fingido verdadero en 1991, sobre una traducción de David Johnston [2013a:178].

33. Me refiero a dos archiconocidos sonetos de Lope («Desmayarse, atreverse, estar furioso») y de Góngora («Cosas, Celalba, he visto extrañas»).

34. Sobre el pasaje y sus fuentes ver las útiles notas de Giuliani en su edición de la comedia. Como ejemplo a contrario de un pasaje en el que Lope utiliza términos exóticos, pero dotando al contexto de un sentido religioso que se integra de modo coherente, puede recordarse el caso de Bar- 
La tercera situación dramática a la que quiero referirme no parece haber extrañado a la crítica hasta que llamé la atención sobre ella en mi artículo de 2016. Detengámonos en su consideración, porque proporciona una nueva clave interpretativa. Se trata del momento decisivo de la historia de Ginés que coincide, no por azar, con el momento más espectacular de la comedia, cuando se produce la apariencia más importante: durante la segunda representación ante Diocleciano, en el tercer acto, aparece un ángel «verdadero» que se dirige a Ginés y se lo lleva volando hacia las alturas, donde de modo oculto tiene lugar su bautismo; tras unos momentos en que los espectadores (Diocleciano, Maximiano y Camila) comentan la desaparición momentánea del —para ellos— ángel «fingido» y de Ginés, reaparece este arrodillado entre cuatro ángeles, tras haber sido bautizado, recitando un soneto. Giuliani edita el pasaje así:

\begin{tabular}{ll} 
Diocleciano & \multicolumn{1}{c}{ Ginés } \\
& $\begin{array}{l}\text { finge ahora que después } \\
\text { que a Jesucristo adoró, } \\
\text { que es el dios de los cristianos, } \\
\text { aquel ángel viene a verle, } \\
\text { a enseñarle y defenderle. }\end{array}$ \\
MAXIMIANO & iQué de encantamentos vanos! \\
DiocLECIANO & Como esos saben hacer. \\
CAMILA & Dirá que está en oración, \\
& que sus sacrificios son \\
& -que una vez los quise ver- \\
& estar todos atendiendo \\
al que una hostia levanta, & porque a aquella forma santa \\
baja su dios.
\end{tabular}

Diocleciano No lo entiendo.

Descúbrase con música, hincado de rodillas; un ángel tenga una fuente, otro un aguamanil levantado, como que ya le echó el agua, $y$ otro una vela blanca encendida, $y$ otro un capillo

laán y Josafat. El acto segundo comienza con Barlaán vestido de mercader mostrando a Zardán una caja con piedras preciosas (crisólitos, balajes, calcedonias, sardónicas, crisopasos), pero entre ellas dice tener reservada una que «vence al sol su hermosura» (v. 905), aludiendo así a la figura de Cristo y comenzando a construir una alegoría al respecto. 
Ginés Señor divino, que miráis y oís los pensamientos, porque en fin sois Dios, y que un profeta hacéis de un rudo Amós, y un Lázaro difunto revivís;

Vos que un ladrón donde reináis subís, porque muriendo se convierte a Vos; Vos, segunda persona de las dos, en cuyo trono celestial vivís,

Vos que del mar sacastes a Jonás y os mostrastes ser Dios en Emaús, bendecid este pan, pues Vuestro es.

Representad conmigo desde hoy más; haced Vos las piedades de Jesús que yo haré los martirios de Ginés.

Esto se cierre todo

(Lope de Vega, Lo fingido verdadero, vv. 2743-2757)

Lo que llamaba mi atención (Rubiera 2016:190) era

la fuerte presencia de elementos relacionados con el sacramento de la Eucaristía, inesperados en el contexto del sacramento del bautismo y concentrados precisamente en este momento crucial, pues no se encuentran en otras partes de la obra. Es especialmente llamativa la locución "bendecid este pan", que tiene un carácter deíctico, quizás señalador de su presencia en escena. ¿Por qué en este momento Lope de Vega habría decidido introducir una oración que se centra precisamente en la Segunda Persona y en el cuerpo de Cristo?

«Hostia», «forma santa [a la que] baja su dios», «Emaús», «este pan»: en pocas líneas hay una condensación de signos que apuntan en la misma dirección en un momento en el que el sacramento del bautismo debería ser el protagonista, porque es el directamente vinculado con la historia de San Ginés. Nada hay en la fuente de Alonso de Villegas que hubiera orientado a Lope hacia esa solución. ${ }^{35}$ Tampoco

35. En ocasiones Lope de Vega podía encontrar ya en la fuente orientaciones precisas para su composición, como en el caso del texto principal sobre el que debió de basarse para la comedia de San 
en la anterior comedia anónima de San Ginés — que quizás conoció Lope- se introducía referencia eucarística, ni décadas más adelante en la obra de tres ingenios, que volvió sobre el mismo tema hagiográfico. ${ }^{36}$ Como en un caso precedente en que establecíamos una comparación con la comedia de San Segundo y con Los locos por el cielo, podemos referirnos ahora, a modo de contraste, a otra comedia religiosa de Lope muy cercana en el tiempo — es bien sabido que esta época entre 1608 y 1614 es particularmente rica en este género- en la que Lope introduce una escena de bautismo del protagonista mediante una apariencia. Se trata de Barlaán y Josafat, de la que se conserva manuscrito fechado el 1 de febrero de 1611. El paralelo es bien significativo, porque Josafat aparece igualmente arrodillado y recitando un soneto, que dice así:

\title{
Descúbrase Barlaán con un aguamanil, Josafat de rodillas y un Ángel en alto con una corona
}

\author{
BARLAÁN Prometo por el agua recibida, \\ soberano Señor de tierra y cielo, \\ un alma, un corazón, un limpio celo \\ y una verdad de tierno amor vestida. \\ Prometo haceros de mi propia vida \\ sacrificio agradable, y cumplirelo \\ siempre que vos digáis: «Hoy en el suelo \\ queda tu sangre, Josafat, vertida». \\ No tuve culpa yo de la desgracia \\ vuestra, puesto que el alma a vos me mueve, \\ pues tuve en desear tanta eficacia;
}

Tirso de Toledo, hoy perdida. Decía el texto-fuente de Alonso de Villegas, muy significativo en este contexto: «San Tirso pedía a Dios en la prisión que tuviese por bien de darle modo cómo fuese baptizado, porque solo era catecúmeno, [...]. fue a cierta parte donde estaba Phileas, obispo de Cesarea, el cual, viendo a san Tirso y conociéndole, teniendo relación de lo que había padecido por Cristo, derribósele a los pies, y lo mismo hizo san Tirso y entre los dos pasaron santas y piadosas cortesías, pidiendo el uno al otro se levantase primero y le bendijese. El obispo le decía: "Bendíceme, pues eres mártir de Cristo". Tirso replicaba: "Aquí he venido por tu bendición y para que me des agua de spíritu santo, porque no he sido baptizado". Baptizole Fileas y el santo hizo una devota oración a Nuestro Señor, dándole gracias por la ropa nueva con que le había vestido, ofreciéndose a beber el cáliz del martirio para asimilarse a su muerte» (en Madroñal 2014:48).

36. Me refiero a El mejor representante, San Ginés, de J. de Cáncer, P. Rosete y A. Martínez de Meneses, de mediados de siglo, sobre la que puede verse mi estudio en torno a sus aspectos metateatrales (Rubiera 2019). 
mas agora que llega a lo que debe, lavadme con el agua de la gracia y quedaré más blanco que la nieve.

(Lope de Vega, Barlaán y Josafat, vv. 1351-1364)

Como puede apreciarse, en este contexto lo esperable es una alusión al agua que lava, que quita las manchas del pecado, y que puede ponerse fácilmente en relación con la sangre de Cristo y con el martirio. Al contrastar el pasaje del bautismo de Ginés y de su oración posterior con una comedia que en este aspecto resulta más típica, creo que se justifica aún mejor la extrañeza a la que me refería en 2016. Puede añadirse, además, que en Lo fingido verdadero el vínculo de Ginés no solo con Cristo - lo que es evidente-, sino con el cuerpo de Cristo, se avanzaba unos versos antes (vv. 2602-2613), en la primera intervención musical cantada que abría la comedia o tragedia «del cristiano bautizado» representada ante Diocleciano, apuntando hacia el Verbo hecho carne:

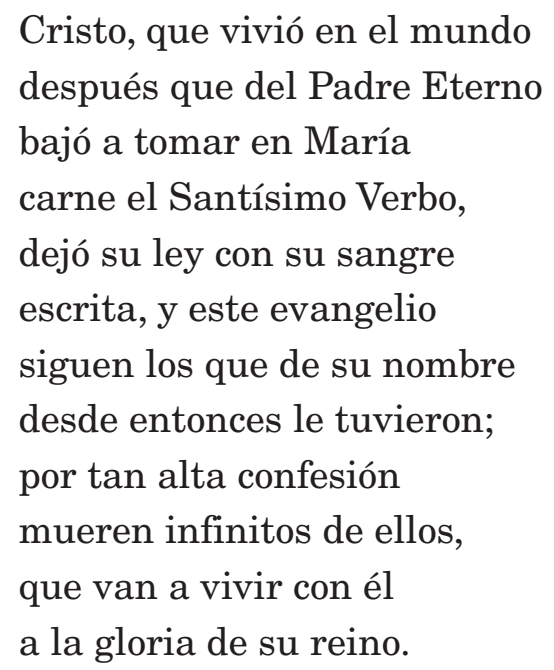

(Lope de Vega, Lo fingido verdadero, vv. 2602-2613)

¿Qué explicación podría darse a esta insistencia en signos que apuntan al cuerpo de Cristo y al sacramento de la eucaristía en un contexto dramático que requiere más bien una focalización en el del bautismo? Al no encontrarse razones dramáticas internas ni indicios en la fuente de la composición, puede proponerse que la presencia de estos elementos procede de razones externas, propias del marco festivo en que tuvo lugar la representación de la comedia, quizás durante 
la festividad de Corpus Christi. Siguiendo mi hipótesis anterior (Rubiera 2016), puede sugerirse también un encargo procedente de alguna de las cofradías del Santísimo Sacramento de Toledo, ciudad tan vinculada a la vida y la obra de Lope, como la de la parroquia de San Vicente o la de San Nicolás. ${ }^{37}$ Recuérdese igualmente la vinculación personal de Lope con las dos cofradías del Santísimo Sacramento fundadas en Madrid en los años 1608 y 1609, que nos hablan con claridad, entre otros indicios, de su profundo interés por el símbolo eucarístico en esta época. ${ }^{38}$

Diocleciano no puede entender el misterio del pan, ni cómo «a aquella forma santa baja su dios» (vv. 2740-2743), porque para un gentil como él el pan es simple elemento material que sirve para el más elemental sustento. Necesitaría que, como al Cuerpo en el auto lopesco de La Maya, el Entendimiento le aclarara:

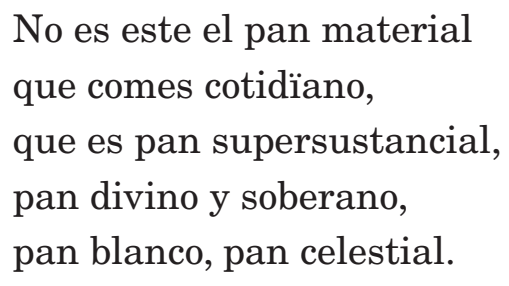

(Lope de Vega, La Maya, p. 325)

37. En Toledo reside Lope desde 1604 a 1610. Ver los trabajos de Madroñal [2013, 2014 y 2017], tan iluminadores sobre Lope como «poeta toledano» y sobre cómo recibió por parte de distintas instancias o personas de la ciudad imperial encargos de comedias religiosas como las de San Tirso, El Hamete de Toledo o El niño inocente de La Guardia en contextos muy particulares. En el texto conservado de Lo fingido verdadero no hay ningún indicio concreto que la asocie a Toledo ni a ninguna ciudad española. Es extraño, por lo tanto, que J. Oleza la vincule con los dramas de hechos famosos de la historia española (Oleza y Antonucci 2013:718). Recuérdese, además, que parroquias de San Ginés como las de Madrid, Toledo o Guadalajara se relacionan con San Ginés de Arlés, no con el Ginés de Roma, el santo representante, aunque desde finales del xvi comenzara a difundirse en medios eruditos la idea de que habría existido un San Ginés martirizado en Madrid, junto a otros cristianos, en tiempos del emperador Juliano.

38. Es bien sabido que en los manuscritos de Lope, a partir de 1610 y hasta 1623, es muy frecuente que aparezca al final de cada acto la invocación «Loado sea el Santísimo Sacramento», a veces abreviado como l.s.e.S.S. (con otras variantes), y por esa época adopta también la costumbre de incluir al comienzo de casi todos los actos un símbolo eucarístico, mediante un pequeño dibujo de dos ángeles arrodillados que sostienen un cáliz con una hostia, como puede apreciarse en catorce autógrafos de comedias entre 1610 y 1617 y en el del auto Las hazañas de David, de 1619. Como recuerda López García [2017:283], en un detallado estudio reciente, Lope «firma por primera y acaso única vez como "Esclavo del Santísimo Sacramento"» en su participación en la justa poética por la fiesta del Santísimo Sacramento celebrada en la iglesia de San Nicolás de Toledo el 25 de junio de 1608. 
Aunque pueda asociarse a un contenido simbólico mediante una comparación, el pan en el mundo pagano de Lo fingido verdadero no tiene «significación» metafísica. Puede partirse y compartirse entre compañeros, como hace Diocleciano en el acto primero, una vez que la vivandera Camila había aparecido con su «cesta de panecillos» («¿Quién compra el buen pan, soldados?», v. 81; «¿Quién quiere pan, quién le quiere?,» v. 91). Diocleciano puede incluso pronunciar palabras como «Tomad del pan, compañeros» (v. 136), «Toma y come, Maximiano» (v. 141), pero en un mundo de gentiles esas palabras agotan su significación en el acto comunicativo, sin posibilidad de remitir a las del «dios cristiano», que desconoce. ${ }^{39}$ Pero como para Diocleciano «la romana religión / toda se funda en agüeros» (vv. 132-133), siente la disposición a interpretar ciertos signos, que contienen algo de misterio, en una dirección que poco a poco apunta a que puede que él esté reservado para altos designios, tras haberle anunciado Camila, como de burla: «cuando tu matares / un jabalí, tú serás / emperador» (vv. 117-119).

$\begin{array}{ll}\text { Diocleciano } & \begin{array}{l}\text { La romana religión } \\ \text { toda se funda en agüeros. } \\ \text { CuRio }\end{array} \\ \text { Come y deja de pensar } \\ \text { en lo que no ha de llegar. } \\ \text { Diocleciano } & \text { Tomad del pan, compañeros, } \\ & \text { que a verme yo por misterio } \\ \text { en el imperio algún día, } & \text { tan bien repartir sabría } \\ \text { como este pan el imperio. } \\ \text { Toma y come, Maximiano, } \\ \text { que has de ser mi coadjutor. }\end{array}$

(Lope de Vega, Lo fingido verdadero, vv. 132-142)

El mundo romano no carece de «misterio», pero solo es descifrable a través de agüeros y de presagios. Tras lanzar Camila su vaticinio, Lope apunta en esa dirección al combinar pensamientos explícitos al respecto, con un uso sutil de una rima que llama la atención por su recurrencia: imperio / misterio. En esta primera aparición (vv. 137-140) comienzan a despertarse en Diocleciano una idea y un presenti-

39. Repárese en que, sin embargo, buena parte de los receptores, cristianos, de la comedia de Lope sí las interpretarían a modo de contraste de las pronunciadas por Cristo en la Última Cena. 
miento que irán tomando cuerpo a medida que avance la acción. Un poco más adelante, con el cadáver del César Aurelio Caro presente, su hijo Numeriano dialoga con Apro y en cierto momento interviene Diocleciano en aparte para completar con su pensamiento lo que acaba de decir Numeriano, pues está oyendo la conversación junto a otros soldados: ${ }^{40}$

Numeriano Carino en Roma impera;

si por César me elige, si me nombra, aunque dudo que quiera

tener igual ni aun de su misma sombra, yo serviré al imperio.

Diocleciano No son estas razones sin misterio.

(Lope de Vega, Lo fingido verdadero, vv. 289-294)

Todavía en este mismo acto se repetirá una vez más la rima, en boca de Apro, ${ }^{41}$ y al comienzo del segundo acto de nuevo Diocleciano la retomará al recordar el hecho decisivo de haber conocido a Camila:

\author{
Por la suprema deidad \\ de Júpiter soberano, \\ que quisiera que el imperio \\ pudiera admitir mujer, \\ y que no debió de ser \\ conocerte sin misterio.
}

(Lope de Vega, Lo fingido verdadero, vv. 1159-1164)

40. Subrayo el hecho de que en mi interpretación la frase de Diocleciano debe decirse aparte, no señalado así por Giuliani en su edición. Para mí es prueba de esa interiorización que poco a poco (convencionalmente, dentro del ritmo acelerado de la acción diseñada por Lope) va haciendo Diocleciano de que es posible que misteriosamente esté llamado a ocupar el puesto de Emperador. Es su primer y único aparte antes del decisivo en el último tramo del primer acto (vv. 887-918).

41. «Es mi yerno, Severio, el más gallardo / príncipe que habrá visto aqueste imperio. / Felicidad de su gobierno aguardo: / no le guardan los cielos sin misterio» (vv. 683-686), dicen las mentirosas palabras de Apro. Nótese que su interlocutor se llama Severio y que, por lo tanto, habría sido muy fácil para Lope colocar su nombre a final de verso para propiciar otra rima, pero le interesa particularmente la de «imperio / misterio». 


\section{UNA ÚLTIMA EXTRAÑEZA}

Desde el soneto de Ginés arrodillado tras su bautismo, nos hemos movido hacia el acto primero, porque una vez identificada la red de signos en torno a la eucaristía como una posible alusión al pan-Cuerpo de Cristo presente en la representación de Lo fingido verdadero, estamos en condiciones de reparar en la recurrencia del signo "pan» en otras partes de la comedia. ${ }^{42}$ Entre esas partes se establecen una simetría y un contraste cuya introducción señalábamos más arriba como uno de los modos de conferir armonía y cohesión en lo que aparentaba ser acumulación de elementos heterogéneos y disonantes. Efectivamente, por un lado, tenemos una serie de pasajes recurrentes en torno al pan y al hecho de que Diocleciano se refiere a él para hacer una comparación entre la acción de partir el pan y la de partir un imperio, como muestra de su buen sentimiento de solidaridad y de agradecimiento. Por otro lado, esta interpretación del pan en el mundo pagano contrasta con la que proporciona el mundo cristiano al indicar Ginés el pan «verdadero» asociado al Cuerpo de Cristo. ${ }^{43}$

Junto al símbolo del pan, se aprecia el juego reiterado con otro signo que cumple una importante función, clara en sus intenciones dentro del mundo pagano, pero que conduce a una nueva extrañeza, la última que analizaremos en este artículo, porque sorprendentemente no se establece con él la simetría o el contraste con el mundo cristiano, que sería de esperar en una comedia religiosa. Se trata del símbolo del laurel.

El laurel en las sienes del César es el signo evidente del imperio y Lope le dará una función dramática y espectacular muy relevante. Con su recurrencia visual y verbal se articulan diferentes partes de la comedia en torno a Diocleciano, convirtiéndose en un motivo conductor de la primera jornada y del comienzo de la segunda. Se evidencia en la primera salida de un emperador a escena, indicándose en acotación «Salga el César Aurelio con su laurel» (v. 192Acot). El signo se carga en seguida de un nuevo sentido, porque en medio de una terrible tormenta el César desafía a los dioses, creyéndose protegido del rayo por la virtud del laurel («¿No ves

42. El recuerdo del pan reaparecerá en estos pasajes: vv. 887-888, 1077-1084; 1113-116; 1141$1148 ; 1169-1170 ; 2107-2109 ; 2119-2129$.

43. No abundo más ahora en la cuestión del simbolismo del pan que he comentado en detalle (Rubiera 2016), también en sus posibles repercusiones sobre la puesta en escena de la comedia. 
que mi sagrado laurel / es a tu furia reservado?», vv. 203-204). Sin embargo, cae fulminado inmediatamente y Diocleciano exclama al verlo: «Los laureles sagrados / no respeta tu furia, cielo impío» (vv. 255-256). A partir de la muerte de Aurelio Caro, se abre la expectativa de quién será el nuevo César, quién se ceñirá el laurel, por lo que serán recurrentes las referencias verbales y las situaciones que lo tienen como eje visual, sobre todo en la tercera parte del acto, hasta que el ejército romano aclame a Diocleciano como emperador al grito de «iQue se le ponga el laurel!» (vv. 978979) al final de esa primera jornada. Efectivamente, a partir del verso 771 la escena se llena literalmente de laureles, cuando los soldados se disponen «a adorar la presencia del César» Numeriano (vv. 777-778), según anuncia la acotación: «En una silla de manos traigan a Numeriano, y los soldados todos con un laurel»(v.770Acot). La alusión verbal al laurel y a «laurear» se hace, entonces, continua (vv. 774, 786, 811, 812, 820, 825-826, 838-839, 857, 883, 957, 975-976, 978-979).

$\mathrm{Al}$ comienzo del acto segundo, Diocleciano ya es Emperador en Roma. Quiere cumplir con su promesa de compartir el imperio con Maximiano, ahora que la Fortuna le ha encumbrado, y para hacerlo evidente a todos, coronará él mismo a su compañero. Hay que subrayar que en este momento se entrelazan los símbolos del pan y del laurel inequívocamente.

\author{
es bien \\ partir contigo también \\ este laurel de mi frente. \\ César te hago; [...] \\ Cuando partimos el pan \\ quitado a los enemigos, \\ éramos buenos amigos; \\ hoy que este imperio nos dan \\ los benignísimos cielos, \\ partámosle entre los dos, [...] \\ (Lope de Vega, Lo fingido verdadero, vv. 1070-1082)
}

En dos ocasiones Diocleciano pide un laurel («Dadme un laurel», v. 1085; «iTraigan un laurel!», v. 1098), mientras la acotación dice «Sacan un laurel» (v. 1099Acot), propiciando que Diocleciano corone a su amigo: «Estas hojas consagradas / pongo de mi propia mano / en tu frente, Maximiano» (vv. 1101-1103). La acotación siguiente 
da entrada a Camila y pone el foco en los dos Césares: «Sale Camila, labradora, en sentándose los dos, ya laureados» (v.1108Acot).

Por lo tanto, es evidente la insistencia en el juego simbólico con este icono visual de gran rendimiento dramático y espectacular, asociado al César Diocleciano. Sin embargo, a partir de este momento de la coronación, desaparece la referencia al laurel, no se juega más con el signo y se desaprovecha la posibilidad de utilizarlo como un elemento de contraste entre el mundo pagano y el mundo cristiano, en el momento final del martirio de Ginés. Ginés bien podría ser coronado por un ángel, para reforzar tanto la simetría estructural como el mensaje sobre el verdadero Dios frente a las fingidas divinidades paganas, entre las que se incluían los mismos césares. He ahí la extrañeza a la que nos referíamos: tal como transmite la Parte XVI el texto de la comedia, una última acotación indica sucintamente: «Descúbrase empalado Ginés» (v. 3102Acot), quien se dirige al pueblo romano en una breve alocución. Sin apoteosis, sin ángeles, sin otro indicio de intervención divina, sin laurel de triunfo en el martirio. Que en la historia de Ginés encaja bien su coronación frente al laureado Diocleciano puede justificarse, además de por razones internas, por cómo la reflejan las otras dos comedias españolas que trataron su vida. La anónima Comedia de San Ginés presenta una escena del tercer acto —en la cárcel— en la que un ángel le pone una guirnalda, diciendo estas palabras:

Hoy tendréis campo reñido

tú y el fiero Emperador

y, aunque él será el vencedor, no quedarás tú vencido,

porque él vencerá por hoy

y tú por siempre en la gloria;

y en prendas de esta victoria

esta corona te doy.

(Comedia de San Ginés, f. 8r)

Más clara es aún si cabe la comedia de El mejor representante, San Ginés, de Cáncer, Rosete y Martínez de Meneses, que cierra la acción con una apariencia espectacular que muestra el triunfo apoteósico del santo. Mientras una acotación indica que ha de verse «una perspectiva redonda en forma de teatro y en medio Ginés en una cruz atravesado de una lanza», otra la complementa señalando «Baja un 
ángel con un laurel al son de las chirimías», quien se dispone a seguir las órdenes de Dios para que su «heroica frente enrame / con este laurel sagrado» (Cáncer, Rosete y Martínez, p. 230), a la vez que suena música celestial.

Sin embargo, Lope, o el texto de su comedia tal como se nos ha transmitido, contempla un final más humano, con la imagen solitaria de Ginés dirigiéndose al pueblo, rompiendo la expectativa de mostrarle triunfante en el martirio, quizás coronado de laurel.

\section{ConcLusión}

Fueran cuales fueran las razones que indujeron a Lope de Vega a escribir Lo fingido verdadero, puede deducirse del texto que se nos ha transmitido que Lope se movió con una enorme libertad creativa a partir de las fuentes histórico-legendarias que le proporcionaban un flos sanctorum y una historia de los emperadores romanos. $\mathrm{Su}$ decisión de construir la comedia sobre la contraposición de Ginés y Diocleciano, así como de dotarles de unos antecedentes bien fundamentados a los momentos decisivos de sus vidas, le llevó a su imaginación a ir mucho más allá de lo que las fuentes librescas le sugerían. Mostrar la mudanza de vida del soldado Diocleciano hasta convertirse en Emperador le conduce a condensar varios años de historia romana a través de episodios significativos en los que mueren violentamente césares y cónsules, cruzados con escenas de la vida militar cotidiana en Mesopotamia o con aventuras nocturnas en la ciudad de Roma en los que surgen lances propios de comedia de capa y espada, que se torna en tragedia de honor. Mostrar la mudanza de vida del actor Ginés le lleva, por un lado, a sumergirle en el mundo del teatro, haciendo de él, además de actor, un poeta y un autor de comedias de gran conciencia artística, que en repetidas ocasiones habla de su arte; por otro lado, le lleva a inventarle una historia de amor y celos con una de sus actrices. Al poner en contacto las dos figuras protagonistas sobre un mismo espacio de ficción, Lope de Vega propiciará que la compañía de Ginés represente en dos ocasiones sendas obras ante Diocleciano y sus invitados, en el acto segundo y en el acto tercero: una de ellas es de enredo amoroso; la otra, «la del cristiano bautizado», es de carácter religioso — y se supone que con función paródica para sus espectadores-, lo que propiciará que a partir de ahí Lo fingido verdadero se transforme en una comedia de mártir en su tramo final, al 
pasar Ginés del plano de la realidad fingida en la obra representada al plano de cristiano verdadero ante Diocleciano.

Con este ambicioso plan en mente, comprobado en diversos análisis, el resultado es una obra que integra numerosos elementos de naturaleza heterogénea y que explora a fondo los límites de la hibridez genérica mediante múltiples combinaciones, que han llegado a desconcertar a veces a los críticos, pues se dan dentro de una estructura cambiante o móvil, en la que además se insertan los diferentes grados de ficcionalidad propiciados por el mecanismo metateatral. A pesar de esta apertura hacia elementos de procedencia diversa, de naturaleza profana o religiosa, Lope pone límites a la introducción de rasgos cómicos, lo que muestra que no está dispuesto sin más a que la pieza se convierta en maremágnum. El hecho de denominarla «tragicomedia» no tiene que ver con que haya partes graves combinadas con ridículas, mezclando a Terencio con Séneca, sino con el hecho de que, sobre un fondo de muertes violentas en escena - de Aurelio Caro a Ginés-, humildes soldados y actores se codeen con césares y cónsules, y dos de ellos, Diocleciano y Ginés, muestren una mudanza de vida espectacular.

Tal como hemos señalado, Lope logra conferir unidad artística al conjunto de personajes y al torrente de acontecimientos de distinto género mediante 1) un tema articulador de los tres actos (la metáfora del theatrum mundi),2) el juego de contraposición entre dos personajes protagonistas, y 3) una red de recurrencias, simetrías y contrastes, acompañada de algunos símbolos de marcado rendimiento dramático y espectacular, como el laurel y el pan. Hay sin embargo dos pasajes que parecen escapar a esta organización estructural: uno de ellos (la canción a Lucinda) puede que sea un elemento ajeno a la primera composición y que haya sido introducido por motivos extradramáticos; el otro (el romance de las fieras extrañas) cumple una función efectista, de puro alarde para el recitante y de claro impacto sobre la imaginación y los oídos del público, sin otro rendimiento para la acción dramática. En todo caso, ambos pasajes, con su aire de injerto superfluo, contribuyen de modo suplementario a la apariencia híbrida de Lo fingido verdadero.

Nada hay de extraño o sorprendente en esta hibridez de Lo fingido verdadero, que encaja perfectamente con varios hechos. En primer lugar, como recordamos al principio mediante una cita de J. Oleza, la mezcla se convierte en un valor fundamental del sistema dramático de la «comedia nueva», no en un simple precepto ocasional de su poética. En segundo lugar, particularmente la comedia hagiográfica 
es un género al que se le ha reconocido la hibridación y la heterogeneidad de sus materiales como una de sus características estructurales. En tercer lugar, la libertad imaginativa de Lope se asienta, y se articula, sobre la variedad — de acciones, de situaciones y de personajes - como medio de representación de la realidad que satisfaga el gusto y las expectativas del público. En cuarto lugar, no es infrecuente que al «poema dramático» se le añadan o injerten pasajes impertinentes a la acción dramática, que, sin embargo, estarían motivados por razones personales del dramaturgo o por efectos pensados para la realización del espectáculo. Hay pues en la textura verbal de una comedia, elementos que proceden de su condición de poema, otros de su condición de drama y otros que son huella de la representación a la que inevitablemente también apunta. Ya, entonces, cada «poema dramático representable» nace marcado por una hibridez constitutiva y a partir de ella puede comprobarse de qué modo concreto se plasma en cada caso dentro de la comedia del siglo XVII o de la obra de Lope de Vega, que tienden igualmente a profundizar en la hibridez. Es lo que ha tratado de mostrar este artículo sobre la hibridación en Lo fingido verdadero, uno de los casos más complejos y ricos de la excepcional dramaturgia lopesca, hibridación que va mucho más allá de la mezcla de elementos de distinta naturaleza profana y religiosa. 


\section{BIBLIOGRAFÍA}

ABEL, Lionel, Metatheatre: A New View of Dramatic Form, Hill and Wang, Nueva York, 1963.

Antonucci, Fausta, «Algunos ejemplos de hibridación genérica en el teatro de Lope: reflexiones al hilo de unas búsquedas en la base de datos ARTELOPE», Teatro de palabras, VII (2013), pp. 141-158.

AntonucCI, Fausta, «Una nueva herramienta para el estudio del teatro clásico español: Calderón digital. Base de datos, argumentos y motivos del teatro de Calderón», Bulletin of the Comediantes, LXX 1 (2018), pp. 79-95.

APARICIO MAYDEU, Javier, «A propósito de la comedia hagiográfica barroca», en Estudio actual de los estudios sobre el Siglo de Oro. Actas del II Congreso Internacional de Hispanistas del Siglo de Oro, ed. M. García, Universidad de Salamanca, Salamanca, 1993, vol. 1, pp. 141-151.

Aragone Terni, Elisa, Studio sulle «comedias de santos» di Lope de Vega, Casa Editrice D’Anna, Messina-Firenze, 1971.

ARTELOPE. Base de Datos y Argumentos del teatro de Lope de Vega, dir. J. Oleza, Universitat de València, 2012-2021, en línea, <https://artelope.uv.es/>. Consulta del 19 de mayo de 2021.

BRyans, J.V., «Fortune, Love and Power in Lope de Vega's Lo fingido verdadero», Revista Canadiense de Estudios Hispánicos, IX 2 (1985), pp. 133-148.

Calderón digital. Base de datos, argumentos y motivos del teatro de Calderón, Proyecto TeSpa, 1570-1700, 2017, en línea, <http://calderondigital.unibo.it/>. Consulta del 19 de mayo de 2021.

CÁncer, Jerónimo, Pedro Rosete y Antonio Martínez, «El mejor representante, San Ginés», en Parte veinte y nueve de comedias nuevas, escritas por los mejores ingenios de España, Joseph Fernández de Buendía, Madrid, 1668, pp. 188-230.

CAnning, Elaine, Lope de Vega's "comedias de tema religioso". Re-creations and Re-presentations, Tamesis, Londres, 2004.

CANONICA, Elvezio, «De la ficción de la verdad a la verdad de la ficción en Lo fingido verdadero de Lope de Vega», en El teatro dentro del teatro: Cervantes, Lope, Tirso y Calderón, eds. I. Andres-Suárez, J.M. López de Abiada y P. Ramírez Molas, Verbum, Madrid, 1997, pp. 99-110.

CANONICA, Elvezio, «El teatro dentro del teatro: desde la verosimilitud hasta la iden- 
tificación en Lo fingido verdadero de Lope de Vega», en Similitud y verosimilitud en el teatro del Siglo de Oro. Vraisemblance et ressemblance dans le théâtre du siècle d'or, ed. I. Ibañez, Ediciones Universidad de Navarra, Pamplona, 2005, pp. 131-148.

Castillejo, David, Las cuatrocientas comedias de Lope. Catálogo crítico, Teatro Clásico Español, Madrid, 1984.

Cattaneo, Maria Teresa, «Il teatro nel mondo e il modo del teatro», introducción a Lope de Vega, Lo fingido verdadero, Bulzoni, Roma, 1992, pp. 7-41.

Cattaneo, Maria Teresa, «Introduzione» a Lope de Vega, La finzione veritiera. Lo fingido verdadero, CUEM, Milano, 2008, pp. 5-35.

Cattaneo, Maria Teresa, «Transformaciones de Ginés, actor y mártir», en La comedia de santos. Coloquio Internacional (Almagro, 1, 2 y 3 de diciembre de 2006), Ediciones de la Universidad de Castilla-La Mancha, Almagro, 2008, pp. 255-268.

CAZés GryJ, J. Dann, «La comedia de santos y el teatro en el Siglo de Oro», Atalanta, III 2 (2015), pp. 37-70.

Comedia de San Ginés, Biblioteca Nacional de España, MSS/14644.

COUDERc, Christophe, «Sobre el género y la intriga secundaria en algunas comedias de santos de Lope de Vega», en La comedia de santos. Coloquio Internacional (Almagro, 1, 2 y 3 de diciembre de 2006), Ediciones de la Universidad de Castilla-La Mancha, Almagro, 2008, pp. 65-84.

Crivellari, Daniele, «Introducción» a Lope de Vega, Barlaán y Josafat, Cátedra, Madrid, 2021, pp. 9-118.

CuRTIUS, Ernst Robert, «Metáforas del teatro», en Literatura europea y Edad Media latina, Fondo de Cultura Económica, México-Buenos Aires, 1955, vol. 1, pp. 203-211. D’ARToIs, Florence, «El teatro en el teatro en Lo fingido verdadero. Nuevo intento de aproximación», en "Por discreto y por amigo». Mélanges offerts à Jean Canavaggio, eds. C. Couderc y B. Pellistrandi, Casa de Velázquez, Madrid, 2005, pp. 181-189.

D’Artois, Florence, y Héctor Ruiz, «Prólogo» a Lope de Vega, El premio de la hermosura, Comedias. Parte XVI, coords. F. d'Artois y L. Giuliani, Gredos, Barcelona, 2017, vol. 1, pp. 55-86.

D’Artois, Florence, y Luigi Giuliani, «La Décimasexta Parte: historia editorial», en Lope de Vega, Comedias. Parte XVI, coords. F. d'Artois y L. Giuliani, Gredos, Barcelona, 2017, vol. 1, pp. 1-38. 
Di PINTO, Elena, «"Entre bestias anda el juego" o la tradición animalística clásica en Lo fingido verdadero», Cuadernos de filología clásica. Estudios latinos, XVII (1999), pp. 199-217.

Dixon, Victor, «"Ya tienes la comedia prevenida [...] la imagen de la vida": Lo fingido verdadero», en En busca del Fénix. Quince estudios sobre Lope de Vega y su teatro, ed.A. García González, TC/12-Iberoamericana-Vervuert, Madrid-Frankfurt am Main, 2013a, pp. 159-182.

Dixon, Victor, «La intervención de Lope en la publicación de sus comedias», en En busca del Fénix. Quince estudios sobre Lope de Vega y su teatro, ed. A. García González, TC/12-Iberoamericana-Vervuert, Madrid-Frankfurt am Main, 2013b, pp. 93-115.

Fischer, Susan L., «Lope's Lo fingido verdadero and the Dramatization of the Theatrical Experience», Revista Hispánica Moderna, XXXIX 4 (1976-1977), pp. 156-166.

GARASA, Delfín Leocadio, Santos en escena (Estudio sobre el teatro hagiográfico de Lope de Vega), Cuadernos del Sur, Bahía Blanca, 1960.

GARCíA REIDY, Alejandro, «El castigo sin venganza o la trágica pasión por lo imposible», en Lope de Vega, El castigo sin venganza, Crítica, Barcelona, 2009, pp. 7-72.

Giuliant, Luigi, «Prólogo» a Lope de Vega, Lo fingido verdadero, en Comedias. Parte XVI, coords. F. d'Artois y L. Giuliani, Gredos, Barcelona, 2017, vol. 2, pp. 737-756.

Hermenegildo, Alfredo, Javier Rubiera y Ricardo Serrano, «La metatrealidad en el teatro de los Siglos de Oro», Teatro de palabras, V (2011), pp. 9-16.

JACQUOT, Jean, «"Le théâtre du monde”, de Shakespeare a Calderón», Revue de littérature comparée, XXXI (1957), pp. 341-372.

López Martínez, José Enrique, «Lope de Vega, poeta del Santísimo Sacramento», Arte Nuevo, IV (2017), pp. 271-334.

Madroñal, Abraham, "Sobre la fecha, fuentes, y otros aspectos de El Hamete de Toledo, de Lope de Vega», Anuario Lope de Vega. Texto, literatura, cultura, XIX (2013), pp. 32-66.

Madroñal, Abraham, «San Tirso de Toledo, tragedia perdida de Lope de Vega», Hipogrifo, II 1 (2014), pp. 23-54.

Madroñal, Abraham, «Nuevos datos sobre El niño inocente de La Guardia, de Lope de Vega», RILCE, XXXIII 1 (2017), pp. 283-301. 
MARín, Diego, La intriga secundaria en el teatro de Lope de Vega, University of Toronto Press-Ediciones De Andrea, Toronto-México D.F., 1956.

MenéndeZ PElAyo, Marcelino, «Lo fingido verdadero», en Obras de Lope de Vega publicadas por la Real Academia Española. Comedias de vidas de santos. Sucesores de Ribadeneira, Madrid, 1894, vol. 4, pp. xxxix-liii.

MeXia, Pero, Historia imperial y cesárea, en la cual en summa se contienen las vidas y hechos de todos los Césares Emperadores de Roma, desde Julio César hasta el Emperador Maximiliano, Ioan Oporino, Basilea, 1547.

Morr, Duncan W., «Lope de Vega, Diderot, Chaliapin and Lo fingido verdadero», Spanish Studies, I 3 (1981), pp. 31-45.

Morrison, Robert, Lope de Vega and the Comedia de Santos, Peter Lang, Nueva York, 2000.

OlezA, Joan, y Fausta AnTonucci, «La arquitectura de géneros en la Comedia Nueva: diversidad y transformaciones», RILCE, XXIX 2 (2013), pp. 689-741.

Orozco Díaz, Emilio, El Teatro y la teatralidad del Barroco, Planeta, Barcelona, 1969.

Palomo, $\mathrm{M}^{\mathrm{a}}$ del Pilar, «Proceso de comunicación en Lo fingido verdadero», en «El castigo sin venganza» y el teatro de Lope de Vega, ed. R. Doménech, Cátedra, Madrid, 1987, pp. 79-98.

Pawlita, Leonie, Staging Doubt. Skepticism in Early Modern European Drama, De Gruyter, Berlin-Boston, 2019.

Real Academia Española, DEL. Diccionario de la Lengua Española, Real Academia Española, Madrid, en línea, <dle.rae.es>. Consulta del 25 de abril de 2012.

RubieRA, Javier, «Restitución textual y visualización espacial: dos casos en Lo fingido verdadero», eHumanista. Journal of Iberian Studies, XXX (2015), pp. 99-114.

RubieRA, Javier, «Lope de Vega y el nuevo arte de escribir comedias de santos: una nueva mirada a Lo fingido verdadero», Symposium, LXX 4 (2016), pp. 187-96.

RubierA, Javier, «La comedia de El mejor representante, San Ginés, de J. Cáncer, P. Rosete y A. Martínez de Meneses: un caso ejemplar de metateatralidad», RILCE, XXXV 3 (2019), pp. 933-966.

RubierA, Javier, «Los Flos Sanctorum y las fuentes de la comedia Lo fingido verdadero de Lope de Vega», en Entre la villa y corte. Trigesima aurea, Actas del XI Congreso de la Asociación Internacional Siglo de Oro (Madrid, 10-14 de julio de 2017), eds. A.M. Martínez Pereira et al., Universidad Nacional de Educa- 
ción a Distancia-Fundación General-Universidad Complutense de Madrid, Madrid, 2020, pp. 659-668.

RUBIERA, Javier, «Consideraciones sobre la comedia palatina en relación con la Primera y con la Segunda Parte de comedias de Calderón», Anuario Calderoniano, XIV (2021), pp. 109-127.

SERÉs, Guillermo, «Consideraciones metateatrales en algunas comedias de Lope de Vega», Teatro de palabras, V (2011), pp. 87-117.

SimerKA, Barbara, «Metatheater and Skepticism in Early Modern Representations of the Saint Genesius Legend», Comparative Literature Studies, XLII 1 (2005), pp. 50-73.

SIRERA, Josep Lluís, «Los santos en sus comedias: hacia una tipología de los protagonistas del teatro hagiográfico", en Comedias y comediantes. Estudios sobre el teatro clásico español, eds. M.V. Diago y T. Ferrer, Universitat de València, Valencia, 1991, 54-76.

TRueblood, Alan S., «Role-Playing and the Sense of Illusion in Lope de Vega», Hispanic Review, XXXII 4 (1964), pp. 305-318.

UmpIeRRe, Gustavo, «Una comedia metafísica de Lope de Vega: Lo fingido verdadero», La Torre. Revista General de la Universidad de Puerto Rico, XXXVIII 107108 y 109-110 (1980), pp. 161-192.

Valbuena Prat, Ángel, El teatro español en su Siglo de Oro, Planeta, Barcelona, 1969.

Valbuena Prat, Ángel, Historia del teatro español, Noguer, Barcelona, 1956.

VEGA, Lope de, The Actor and the Emperor or, Make-believe Come True: A New Rhyming verse translation of "Lo fingido verdadero» (1608), trad. D. Matthews, Juan de la Cuesta, Nueva York, 2020.

VEGA, Lope de, Arte nuevo de hacer comedias, ed. E. Rodríguez, Castalia-AC/E, Madrid, 2011.

VEGa, Lope de, Barlaán y Josafat, ed. D. Crivellari, Cátedra, Madrid, 2021.

VegA, Lope de, Comedias. Parte XVI, coords. F. d'Artois y L. Giuliani, Gredos, Barcelona, 2017a.

VEGA, Lope de, Lo fingido verdadero, ed. L. Giuliani, en Comedias. Parte XVI, coords. F. d'Artois y L. Giuliani, Gredos, Barcelona, 2017b, vol. 2, pp. 735-893.

VEGA, Lope de, Obras de Lope de Vega publicadas por la Real Academia Española. Comedias de vidas de santos, Sucesores de Rivadeneira, Madrid, t. IV, 1894. 
VEGA, Lope de, El peregrino en su patria, ed. J.B. Avalle-Arce, Castalia, Madrid, 1973.

VeGA, Lope de, «El Teatro a los Letores», en Décimaquinta Parte de las comedias de Lope de Vega Carpio, Viuda de Alonso Martín, Madrid, 1621, s.p.

VILANova, Antonio, «El tema del Gran Teatro del Mundo», Boletín de la Real Academia de Buenas Letras de Barcelona, XXIII (1950), pp. 153-188.

Villegas, Alonso de, Flos Sanctorum, y Historia general, de la vida y hechos de Jesucristo, Dios y Señor nuestro, y de todos los santos de que reza y hace fiesta la Iglesia católica, [...] junto con la vida de los Santos propios de España, y de otros Extravagantes, Viuda de Juan Rodriguez, Toledo, 1591.

Villegas, Alonso de, Fructus Sanctorum, y quinta parte de Flos Sanctorum, Juan Masselin, Cuenca, 1594.

Vossler, Karl, Lope de Vega und sein Zeitalter, Oskar Beck, München, 1932; Lope de Vega y su tiempo, trad. R. de la Serna, Revista de Occidente, Madrid, 1933.

Wilson, Edward M., y Duncan MoIr, Historia de la literatura española. Siglo de Oro: teatro (1492-1700), Ariel, Barcelona, 1998.

Zugasti, Miguel, «Teatro en el teatro (TeT): cuatro ejemplos en Cervantes, Lope, Tirso y Vélez», Teatro de palabras, V (2011), pp. 57-85. 